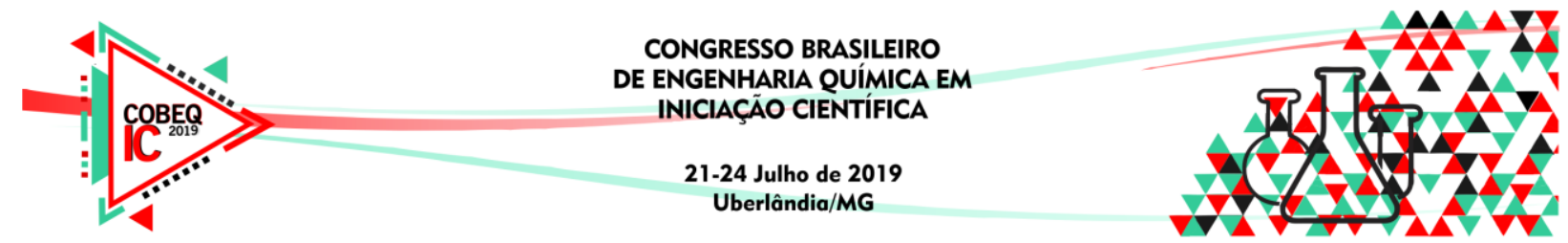

\title{
PRODUÇÃO DE BIOHIDROGÊNIO E AVALIAÇÃO DOS METABÓLITOS PRODUZIDOS POR BACTÉRIAS PÚRPURAS NÃO-SULFUROSAS A PARTIR DE MELAÇO DE SOJA
}

\author{
P. S. LAMOUNIER ${ }^{1}$, J. B. VILLANI ${ }^{1}$ e V. L. CARDOSO ${ }^{1}$ \\ ${ }^{1}$ Universidade Federal de Uberlândia, Faculdade de Engenharia Química \\ E-mail para contato: priscilla.lamounier@ hotmail.com
}

RESUMO - O risco da escassez energética nas próximas décadas tem impulsionado a pesquisa pela busca de uma produção sustentável do hidrogênio, como a fotofermentação utilizando um substrato, como o melaço de soja. As bactérias fotossintetizantes são capazes de converter ácidos orgânicos ou biomassa em hidrogênio na presença de luz e em condições anaeróbias, nesse contexto destacam-se Rhodopseudomonas palustris e Rhodobacter capsulatus. O presente trabalho mostra uma produtividade de $6,87 \mathrm{mmol} \mathrm{H}_{2} / \mathrm{L}$.dia para as $R$. palustris $34 \%$ maior que as $R$. capsulatus.

\section{INTRODUÇÃO}

Atualmente, o uso irrestrito das fontes energéticas de origem fóssil para a obtenção de combustíveis, poderá reduzir irreversivelmente a capacidade de abastecimento das mesmas, uma vez que não são renováveis. Nesse contexto, a produção biológica de hidrogênio é vantajosa, pois libera uma alta quantidade energética por unidade de peso (143 GJ/ton) e não emite dióxido de carbono durante a combustão, e ainda caracteriza-se por ser uma fonte energética renovável. Embora existam certas dificuldades na comercialização de hidrogênio, tais como, alto custo de produção, técnicas de armazenamento e distribuição, ele é considerado um recurso potencial em substituição a combustíveis fósseis (Basak et al., 2016; Tian et al., 2010).

A produção de hidrogênio por bactérias púrpuras não-sulfurosas (PNS) é devido à presença da enzima nitrogenase em condições deficientes de oxigênio, utilizando a energia da luz e vários ácidos orgânicos. Na ausência de nitrogênio, e sob condições anaeróbias, a nitrogenase é capaz de formar hidrogênio em uma reação irreversível, sendo consumidos quatro ATP por mol de $\mathrm{H}_{2}$ produzido, como mostra a Equação 1. Na presença de nitrogênio, a enzima possui a capacidade de reduzir o gás (N2) à amônia (NH3), Equação 2 (Oliveira, 2014; Basak et al., 2014).

$$
\begin{aligned}
& 2 \mathrm{H}++2 \mathrm{e}^{-}+4 \text { ATP } \rightarrow \mathrm{H}_{2}+4(\mathrm{ADP}+\mathrm{Pi}) \\
& \mathrm{N}_{2}+8 \mathrm{H}++8 \mathrm{e}^{-}+16 \text { ATP } \rightarrow 2 \mathrm{NH}_{3}+\mathrm{H}_{2}+16(\mathrm{ADP}+\mathrm{Pi})
\end{aligned}
$$

A produção de hidrogênio por fotofermentação depende de muitos parâmetros como a atividade das enzimas nitrogenase e hidrogenase, proporção de carbono e nitrogênio nos meios de produção, idade do inóculo das bactérias PNS, fonte e intensidade de luz aplicada, 


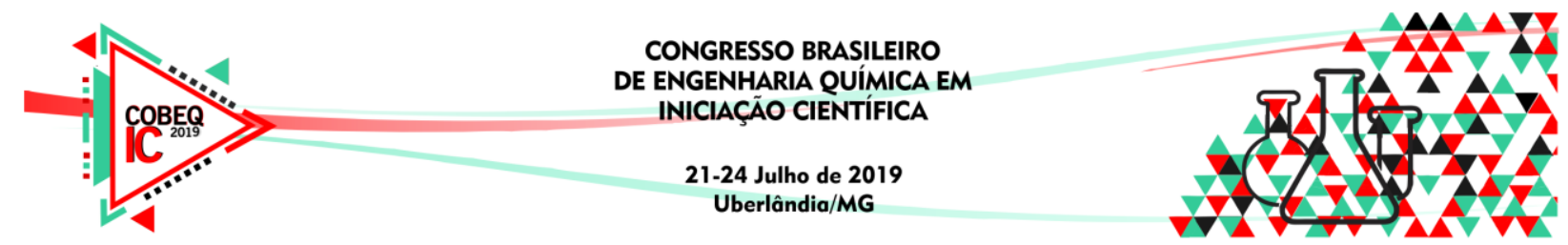

$\mathrm{pH}$, temperatura dentre outros fatores que afetam a eficiência, termos globais de rendimento e taxa de produção simultaneamente (Basak et al., 2014).

Diversas culturas puras são usadas na produção biológica de hidrogênio. Em alguns casos a intenção do uso de culturas puras é determinar as características de crescimento, produtos de fermentação e rendimentos de hidrogênio. Uma das principais vantagens de utilização de culturas puras se dá pela possibilidade de manipulação do metabolismo microbiano, por meio do controle das condições de cultivo. As culturas puras são muito sensíveis a contaminações e seu uso demanda aplicação de condições de assepsia. As bactérias fotossintéticas produtoras de hidrogênio mais conhecidas são $R$. sphaeroides, $R$. capsulatus, Rhodobacter sulidophilus, Rhodopsuedomonas sphaeroides, $R$. palustris (Ntaikou, Antonopoulou e Lyberatos, 2010).

Diversos substratos têm sido utilizados para a produção fermentativa de hidrogênio, como glicose, sacarose e amido, porém tem um elevado custo, o que não torna o processo viável economicamente. Estudos mais recentes utilizaram resíduos orgânicos como substrato para a produção de hidrogênio. Dentre as matérias-primas destacam-se: resíduos municipais, industriais e agrícolas, como o soro de leite, melaço de cana-de-açúcar, de beterraba e de soja, ricos em açúcares ou ainda outros resíduos ricos em material lignocelulósico, tais como resíduos de destilarias, indústrias de papel e químicas (Kothari et al., 2012; Show et al., 2012).

Neste contexto, este trabalho propôs a produção de hidrogênio empregando as Rhodopseudomonas palustris e Rhodobacter capsulatus e utilizando o melaço de soja como substrato.

\section{MATERIAL E MÉTODOS}

Para o seguinte trabalho foram utilizadas cepas de bactérias púrpuras não-sulfurosas, as Rhodopseudomonas palustris e Rhodobacter capsulatus (DSMZ - German Collection of Microorganisms and Cell Culture), no processo de fotofermentação. O cultivo foi realizado em meio basal RCV (Weaver et al., 1975) com o pH ajustado para 6,8, em frascos Duran de $500 \mathrm{~mL}$, no qual $60 \%$ foi preenchido com meio de cultura e inóculo e headspace foi saturado com gás argônio. Os frascos foram mantidos em uma câmara de germinação a $30 \pm 1{ }^{\circ} \mathrm{C}$, com iluminação de 2200 lux. No período de 10 a 12 dias, as cepas foram centrifugadas e o sedimentado era suspendido em um novo meio de cultura.

O meio fermentescível utilizado nos experimentos de fotofermentação foi o próprio meio basal RCV acrescido de $20 \mathrm{~g} / \mathrm{L}$ de melaço de soja, o substrato utilizado para a produção fermentativa de hidrogênio com alta concentração de açúcares. Os ensaios de fotofermentação foram realizados em reatores de $50 \mathrm{~mL}$ (frascos de penicilina), em duplicata. Foram conduzidos à temperatura de $32 \pm 1{ }^{\circ} \mathrm{C}$ e intensidade luminosa de 2200 lux. O volume reacional foi de $37,5 \mathrm{~mL}$, de meio a ser fermentado e inóculo. $\mathrm{O}$ headspace foi preenchido com gás argônio, caracterizando assim um ambiente anaeróbio. 


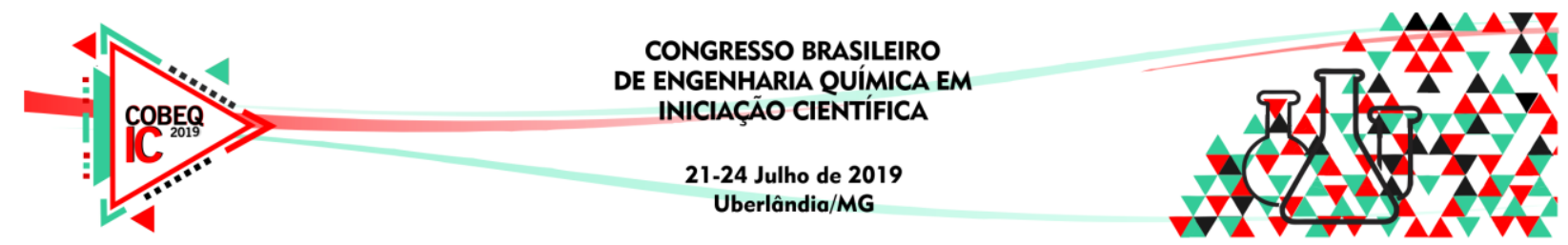

Após a preparação dos reatores, eles foram tampados com septo de borracha butílica e lacrados com cápsulas de alumínio. O biogás produzido foi coletado a partir de seringas graduadas e posteriormente armazenados em ampolas gasométricas para análises. Foram retiradas amostras $\mathrm{O}$ biogás produzido pelo sistema fermentativo foi quantificado por um medidor de vazão e, posteriormente coletado em ampolas gasométricas para a análise da composição, por cromatografia gasosa. Cada amostra retirada foi centrifugada por 10 min a $8000 \mathrm{rpm}$, para que a concentração de metabólitos no sobrenadante fosse medida por cromatografia líquida de alta performance (HPLC, Shimadzu modelo LC-20A proeminência, Supelcogel, coluna C-610H), em que os ácidos orgânicos foram detectados por luz ultravioleta e os açúcares foram detectados por índice de refração. $O$ gás produzido foi coletado em seringas graduadas e sua composição determinada por cromatografia gasosa utilizando Cromatógrafo Shimadzu modelo GC 17-A, equipado com detector de condutividade térmica e coluna capilar Carboxen 1010 (comprimento 30 m, diâmetro interno de $0,53 \mathrm{~mm})$.

Produtividade $=\frac{\mathrm{mmol} \mathrm{H2} \mathrm{reacional}}{\text { volume(L) } \times \text { tempo de fermentaçẫo(dia) }}$

\section{RESULTADOS E DISCUSSÃO}

Para as duas cepas houve uma produção significativa de hidrogênio, mas as $R$. palustris tiveram uma produtividade $34 \%$ maior que as $R$. capsulatus, como mostra a Figura 1. Apesar das $R$. palustris de começar com uma produtividade de $1,35 \mathrm{mmol} \mathrm{H} 2 / \mathrm{L}$.dia, frente a uma produtividade de $1,50 \mathrm{mmol} \mathrm{H} 2 / \mathrm{L}$.dia das $R$. capsulatus. Porém, a partir do quarto dia as Rhodopseudomonas palustris já se destacam, chegando a uma produtividade de $6,87 \mathrm{mmol}$ $\mathrm{H}_{2} /$ L.dia.

Figura 1- Produtividade de Hidrogênio no decorrer da fotofermentação para as cepas $R$. palustris ( $\mathbf{\Delta})$ e $R$. capsulatus (*)

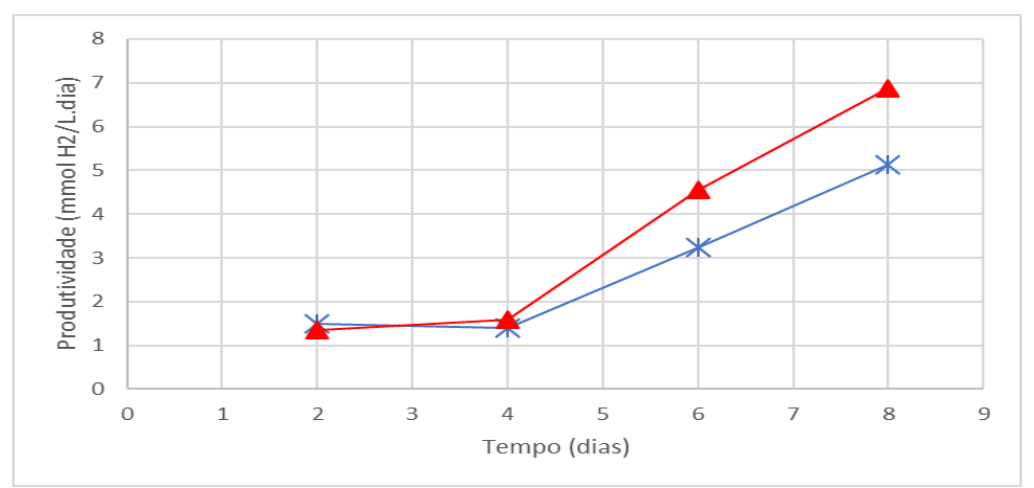

A uma grande diferença entre as cepas referente aos metabólitos existentes durantes a fotofermentação, como mostra a Tabela 1. Assim como o que mostra os trabalhos de Moreira et al. (2016), a produção de ácido butírico ocorre após um tempo decorrido do início da fermentação. Observa-se que para as cepas $R$. capsulatus, não houve presença do ácido butírico e o ácido propiônico pareceu após o segundo dia de fermentação, chegando a 0,197 

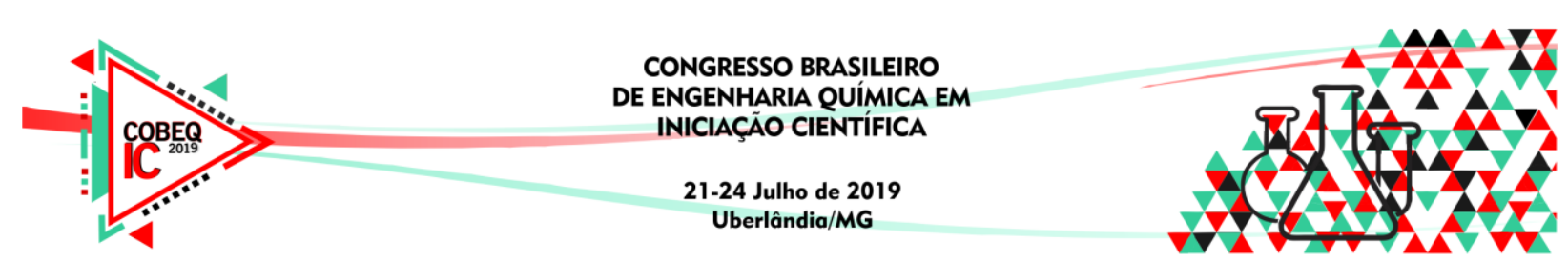

g/L. Houve uma maior variação na concentração do ácido cético, sendo consumido e produzido durante o experimento, sendo que no início do experimento ele apresenta uma concentração de $0,679 \mathrm{~g} / \mathrm{L}$ e terminando a fotofermentação com uma concentração de 1,015 $\mathrm{g} / \mathrm{L}$. Para as cepas $R$. palustris, o ácido propiônico aparece antes das primeiras 48 horas de experimento, com uma concentração de $0,120 \mathrm{~g} / \mathrm{L}$ e ao término com uma concentração $29 \%$ maior. O ácido butírico apareceu após o quarto dia com uma concentração de 1,275 g/L e com uma queda de $86,9 \%$ na sua concentração até o final do experimento. A concentração do ácido acético aumentou no início da fotofermentação, saindo de uma concentração de 0,679 $\mathrm{g} / \mathrm{L}$ para 1,006 g/L no segundo dia, aumentando para 1,085 g/L no final.

Tabela 1 - Metabólitos produzidos durante a fotofermentação

\begin{tabular}{|c|c|c|c|c|c|c|}
\hline Tempo (dias) & & 0 & 2 & 4 & 6 & 8 \\
\hline \multirow{4}{*}{ R. capsulatus } & ácido lático (g/L) & 4,455 & 3,876 & 3,905 & 3,474 & 3,900 \\
\cline { 2 - 7 } & ác. acético (g/L) & 0,679 & 0,213 & 1,041 & 0,756 & 1,015 \\
\cline { 2 - 7 } & ac. propiônico (g/L) & - & - & 0,165 & 0,122 & 0,197 \\
\cline { 2 - 7 } & ac. butírico (g/L) & - & - & - & - & - \\
\hline \multirow{4}{*}{ R. palustris } & ácido lático (g/L) & 4,454 & 3,369 & 3,756 & 3,153 & 3,517 \\
\cline { 2 - 7 } & ác. acético (g/L) & 0,679 & 1,006 & 1,057 & 1,069 & 1,085 \\
\cline { 2 - 7 } & ac. propiônico (g/L) & - & 0,120 & 0,162 & 0,197 & 0,154 \\
\cline { 2 - 7 } & ac. butírico (g/L) & - & - & - & 1,275 & 0,166 \\
\hline
\end{tabular}

Sobre o consumo de açúcares, observa-se que houve um consumo de $45 \%$ pelas $R$. palustris e $31,85 \%$ pelas $R$. capsulatus de açúcares totais. Lembrando que há a degradação do tetrassacarídeo e de trissacarídeo, o que gera aumento na concentração dos monossacarídeos, mas, de maneira geral, são consumidos. A Figura 2 mostra as concentrações de açúcares durante a fotofermentação.

Figura 2 - Variação da concentração de açúcares durante a fotofermentação com as cepas: (a) R. capsulatus e (b) R. palustris

(a)

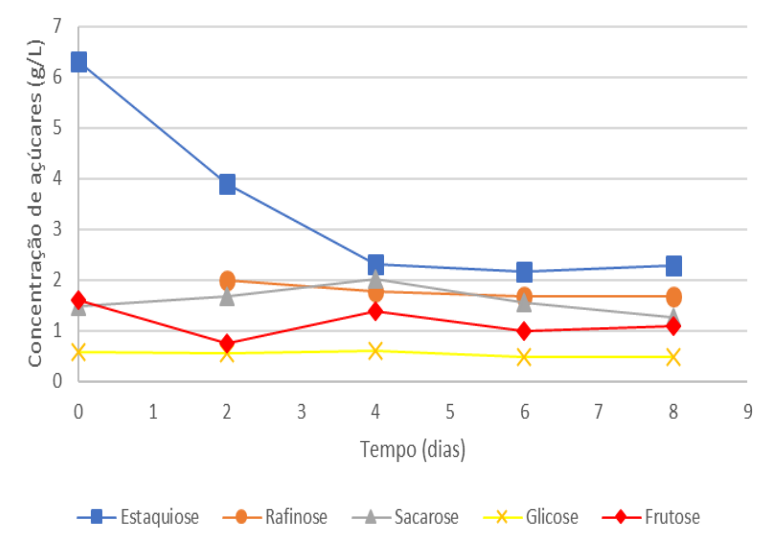

(b)

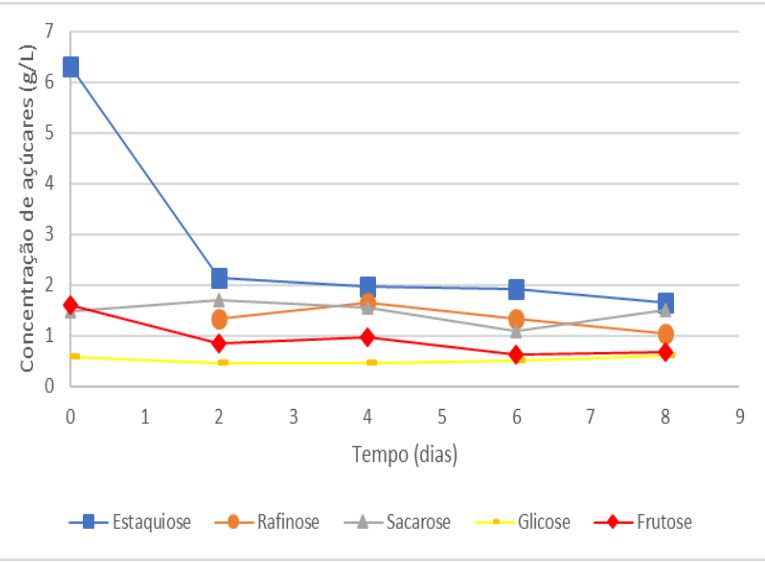




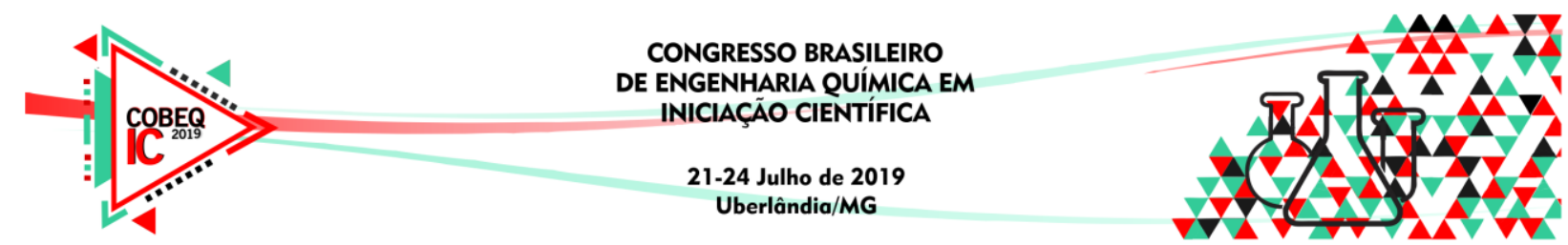

\section{CONCLUSÃO}

Com as análises dos resultados, podemos concluir que as bactérias não-sulfurosas são capazes de produzir biohidogênio por fotofermentação utilizando como substrato o melaço de soja. A cepa $R$. palustris se mostrou com um maior consumo de açúcares e uma maior produtividade e, enquanto a $R$. capsulatus houve a presença de ácido lático, acético e propiônico, as $R$. palustris geraram também o ácido butírico como metabólito.

\section{AGRADECIMENTOS}

Os autores agradecem ao CNPq, CAPES, FAPEMIG, Fau e Vale S.A. pelo apoio e incentivo à pesquisa.

\section{REFERÊNCIAS}

BASAK, N., JANA, A. K., DAS D. CFD modeling of hydrodynamics and optimization of photofermentative hydrogen production by Rhodopseudomonas palustris DSM 123 in annular Photobioreactor, International Journal of Hydrogen Energy, 41, 7301 - 7317, 2016.

BASAK, N.; JANA, A. K.; DAS, D.; SAIKIA. Photofermentative molecular biohydrogen production by purple-non-sulfur (PNS) bacteria in various modes: The present progress and future perspective. International Journal of Hydrogen Energy, v. 39, p. 6853-6871, 2014.

KOTHARI, R.; SINGH, D.P.; TYAGI, V.V. TYAGI, S.K. Fermentative hydrogen production - An alternative clean energy source. Renewable and Sustainable Energy Reviews, v. 16, p. 2337-2346, 2012.

MOREIRA, D. V., GONÇALVES, G. T. I., MOREIRA, F. S., BATISTA, F. R. X., FERREIRA, J. S., CARDOSO, V. L. Fotofermentação usando melaço de soja como substrato por Rhodobacter capsulatus e Rhodopseudomonas palustris. XXI Jornada em Engenharia Química. 214-218, 2016.

NTAIKOU, I.; ANTONOPOULOU, G.; LYBERATOS, G. Biohydrogen production from biomass and wastes via dark fermentation: a review. Waste and Biomass Valorization, v. 1, p. 21-39, 2010.

OLIVEIRA, T. V. Avaliação da produção de hidrogênio empregando bactérias fotossintetizantes. Dissertação de Mestrado. Universidade Federal de Uberlândia, 91 p, 2014. 
SHOW, K.Y.; LEE, D.J.; TAY, J.H.; LIN, C.Y.; CHANG, J.S. Biohydrogen production: Current perspectives and the way forward. International Journal of Hydrogen Energy, v. 37, p. 15616-15631, 2012.

TIAN. X.; LIAO. Q.; ZHU. X.; WANG. Y., ZHANG. P.; LI. J.; WANG. H. Characteristics of a biofilm photobioreactor as applied to photo-hydrogen production. Bioresource Technology, v. 101, p. 977-983, 2010.

WEAVER, P. F.; WALL, J. D.; GEST, H. Characterization of Rhodopseudomonas capsulate. Archives of Microbiology, v. 105, p. 207-216, 1975. 